\title{
BONDAD Y SABIDURÍA EN KANT
}

\author{
Salvi TURRÓ, UB.
}

Barcelona, octubre 2003

RESUMEN: Partiendo de los elementos suministrados por el análisis transcendental de las facultades, especialmente en el terreno de la razón práctica y del Juicio, se ofrece aquí una reconstrucción de la comprensión kantiana de la bondad desde la perspectiva del hombre real (sano entendimiento común, doctrina de la virtud), estableciéndose a la vez los caracteres y limites de la sabiduria propia del hombre moral. Ello permite reinterpretar los factores de continuidad y ruptura entre la tradición filosófica clásica y el giro transcendental en un tema tan central como el de la "sabiduría del mundo".

Mientras que el tema del bien (das Gut), y más específicamente del bien supremo (das höchste Gut), es ampliamente tratado por Kant y configura uno de los núcleos fundamentales de su filosofía ${ }^{1}$, no ocurre lo mismo con la cuestión de la bondad (die Güte), que propiamente no constituye objeto de reflexión temática en su obra ${ }^{2}$. Esta aparente paradoja no es tal si consideramos que el sentido moderno del término bondad ${ }^{3}$ —en alemán com en las lenguas románi-

' Ya en el Canon de la KrV (A 810/B 838 ss.) al fijar el marco conceptual para responder al tercer interrogante de la razón, y más detenidamente a lo largo de la segunda sección de la dialéctica de la $\mathrm{KpV}$ (Ak, V, 100 ss.) al tematizar los problemas inherentes al objecto de la razón práctica.

${ }^{2}$ Una simple comprobación del léxico en la obra completa (cf. versión en soporte electrónico de la Academia: Kant im Kontext 2000, Karsten Worm InfoSoftware, Berlin, 2001) ya es significativa: mientras que la secuencia hochst*-Gut da un total de 113 ocurrencias, la secuencia die- Güte da sólo un total de 33 ocurrencias y prácticamente todas ellas como «bondad divina».

${ }^{3}$ Como discutiremos en la última parte del artículo, este sentido moderno, en el que se situa plenamente Kant, es radicalmente diferente del que podía tener el término para los antiguos, evidenciándose al máximo tal oposición precisamente en la temática de la "sabiduría del mundo" resultante de la moralidad. Para seguir la cuestión en las filosofias antiguas véase: $\mathrm{R}$. Brague, La sagesse du monde, París, Fayard, 1999. 
cas - equivale a "calidad de bueno" en tanto que "natural inclinación a hacer el bien ${ }^{4}$, es decir, designa la cualidad específica del «hombre bueno».

En efecto, el hombre bueno lo es en su conducta inmediata y lo es con anterioridad a toda reflexión filosófico-crítica. El hombre bueno o la bondad constituyen uno de esos supuestos de que parte el filósofo transcendental y cuyas condiciones de posibilidad trata justamente de sacar a la luz, pero cuya existencia es previa e independiente de la filosofía. Igual que los principios transcendentales del entenimiento son usados por el físico sin necesidad de haber leído la $\mathrm{KrV}$, la bondad se encuentra ya en la vida cotidiana sin necesidad de pasar por la $\mathrm{KpV}$. Es claro que la filosofía transcendental busca los principios y justificación de tales facta inmediatos, pero no los crea ni produce. Con respecto a ellos el filósofo crítico procede como el químico ${ }^{5}$ al emplear un método analítico o regresivo $^{6}$ : parte de la forma inmediata en que la conciencia común opera como un todo para, dividiéndola en sus componentes elementales, remontarse a sus últimas condiciones de posibilidad. Justamente este procedimiento analítico da a la crítica su estructura sistemática como ciencia completa y acabada ${ }^{7}$ : Doctrina de los Elementos donde se descompone las diversas facultades de la mente, y Doctrina del Método donde se extraen las reglas procedimentales resultantes.

El supuesto inherente al proceder transcendental es, pues, la operatividad inmediata de nuestras facultades en el mundo, el ejercicio espontáneo de la razón en la realidad cotidiana. Y ello más, si cabe, en el terreno práctico que en el teórico. En el ámbito teórico la apelación al sano entendimiento humano (gensunder Menschenverstand) debe reconocer que el uso correcto del entendimiento común (gemeiner Verstand) en los problemas concretos tiende a extraviarse cuando se enfrenta a las cuestiones puramente especulativas de la metafí$\mathrm{sica}^{8}$, mientras que "la verosimilitud y el sano entendimiento humano tienen ciertamente un uso útil y correcto, pero según principios totalmente propios cuya autoridad depende siempre de la relación con lo práctico»" ${ }^{9}$. Por ello, ya en la $\mathrm{KrV}$ se establece claramente que la razón humana, que en el terreno teórico ha de ser disciplinada, en el práctico es canónica, i.e. inmediatamente legislado-

\footnotetext{
${ }^{4}$ Diccionario de la lengua española, Real Academia Española, 21.a edición, 1992.

${ }^{5}$ Prolegomena (Ak, IV, 366).

${ }^{6}$ Ibíd. (Ak, IV, 263, 276).

${ }^{7} \mathrm{KrV}$ (A 13/B 27).

${ }^{8}$ Prolegomena (Ak, IV, 369-370).

${ }^{9}$ Ibíd. (Ak, IV, 371).
} 
ra de principios a priori ${ }^{10}$; y en la $\mathrm{KpV}$ son constantes las referencias al entendimiento común como lugar inmediato de la moralidad y capacidad correcta de juicio sobre las máximas morales ${ }^{11}$.

Se entiende así que la bondad, aún siendo el supuesto último sobre el que descansa y al que remite la filosofía práctica kantiana, no constituya un objecto terminológicamente tematizado: el hombre bueno, el entendimiento común que juzga y actúa de manera moralmente correcta se dan en la vida inmediata y no en otro lugar. La filosofía transcendental, descomponiendo tal inmediatez, la retrorae a sus condiciones de posibilidad y hace comprensibles sus elementos y principios. Pero, por eso mismo, la bondad no se halla en los elementos así separados y escindidos por el filósofo, sino en la unidad inmediatamente operativa que constituye la vida de la consciencia común.

Por tanto, un intento de "reconstrucción" de la comprensión kantiana de la bondad deberá proceder con el método inverso al de la crítica transcendental: sólo la síntesis de los elementos descompuestos por el análisis filosófico puede darnos aquella unidad vital inmediata que constituye la cualidad del hombre bueno. Con tal finalidad sintética dirigiremos al texto kantiano la preguna por las características de la persona moralmente buena. Lo cual comporta considerar al menos tres aspectos: (1) las facultades constitutivas de la moralidad, (2) el modo de vida (éthos) resultante de su ejercicio, y (3) la sabiduría del mundo (Weltweisheit) del hombre moral.

${ }^{10} \mathrm{KrV}, \mathrm{A} 796 / \mathrm{B} 824$.

${ }^{11}$ Algunos pasajes significativos a título de ejemplo: "Qué forma se adecúa en la máxima a una legislación universal y cuál no, esto puede distinguirlo el entendimiento común sin instrucción" ( $\mathrm{KpV} ; \mathrm{Ak}, \mathrm{V}, 27)$; "el hecho antes citado es innegable, basta con analizar el juicio que emiten los hombres sobre la legalidad de sus acciones..." ( $\mathrm{KpV} ; \mathrm{Ak}, \mathrm{V}, 32$ ); «si la voz de la razón en relación a la voluntad para dirigir la moralidad a su fundamento no fuera tan clara, tan audible, tan perceptible incluso para el hombre más común..." (KpV; $\mathrm{Ak}, \mathrm{V}, 35)$; "tan claros y nítidos estan trazados los límites entre la moralidad y el egoismo que incluso la mirada más común no puede equivocarse al distinguir si algo pertenece a una o al otro" ( $\mathrm{KpV} ; \mathrm{Ak}, \mathrm{V}, 36)$; «lo que haya que hacer según el principio de la autonomía de la voluntad es completamente fácil de saber sin necesidad de reflexionar para el entendimiento más común" (ibíd.); "por tanto, el enjuiciamiento de lo que haya que hacerse según ella [la ley moral] no es tan difícil que no sepa hacerlo el entendimiento más común e inexperto, incluso sin conocimiento del mundo" (ibíd.). 
Es sobradamente conocida la fórmula con que Kant expresa el fundamento de la moralidad: "Actúa de tal manera que la máxima de tu voluntad a la vez pueda valer siempre como principio de una legislación universal» ${ }^{12}$. Se olvida con frecuencia, empero, que tal fórmula se sitúa en el nivel conceptualmente técnico del filósofo transcendental y, por tanto, enuncia abstactamente - desde las exigencias analíticas de la filosofía académica- aquello que, como decíamos antes, constituye el sentido y ejercicio inmediatos de la moralidad en el hombre real. En la medida que aquí preguntamos por la bondad del hombre real y dado que la ley establece la moralidad en la exigencia de universalización de las máximas, es claro que el hombre obra bien cada vez que (1) toma una decisión tal que (2) obedece a una regla que sea válida para todos.

Decidir es un acto propio de un arbitrio dotado de libertad en tanto que "capacidad de iniciar un estado por si mismo cuya causalidad no se encuentra a su vez bajo otra causa según la ley de la naturaleza» ${ }^{13}$. Ahora bien, lo propio de una decisión moral consiste en que esa "absoluta espontaneidad de las causas» ${ }^{14}$ no se determina indistintamente por cualquer posibilidad, sino que adopta un sentido preciso: el de una regla universalmente válida. En la medida que la libertad como principio absoluto de acción sólo constituye fuente de moralidad si se determina de un determinado modo, tal libertad comporta el ejercicio de las facultades de discriminación racional-conceptual y, por ello, se vincula indisolublemente a la razón (práctica): tal es la facultad usualmente denominada voluntad. Es precisamente en este sentido de libertad determinada por motivos racionales que Kant puede decir que «no es posible pensar nada ni en el mundo ni tampoco fuera de él que pueda considerarse como bueno sin limitación, si no es solamente una buena voluntad» ${ }^{15}$.

Fundamentalmente, pues, la bondad humana consiste en tener una buena voluntad, i.e. en decidirse por máximas de validez universal. Según esto, toda decisión moral presupone la capacidad de emitir un juicio sobre la universabilidad o no de una acción; pero toda acción siempre se da en unas circunstancias concre-

\footnotetext{
${ }^{12} \mathrm{KpV}(\mathrm{Ak}, \mathrm{V}, 30)$.

${ }^{13} \mathrm{KrV}, \mathrm{A} 533 / \mathrm{B} 561$.

${ }^{14} \mathrm{KrV}, \mathrm{A} 446 / \mathrm{B} 474$.

${ }^{15}$ Fund. Metaf. Cost. (Ak, IV, 393).
} 
tas. Por tanto, la buena voluntad exige una adecuado discernimiento de lo universal y lo particular: ya sea en el sentido de saber aplicar una regla universal ya establecida a un particular dado, ya sea en el sentido de saber generar una regla nueva para un paticular no subsumible bajo ninguna otra anteriormente dada. Pues bien, la facultad consistente en relacionar lo particular con lo universal es el Juicio (Urteilskraft $)^{16}$-ya sea en su uso teórico ${ }^{17}$ como en su uso práctico ${ }^{18}$-, de donde se sigue que la buena voluntad remite a su vez a la capacidad de juzgar como el eje mismo de la moralidad.

Ahora bien, el Juicio es una facultad peculiar: como transita entre universal y particular, entre principios y datos, entre reglas y casos, su uso no puede explicitarse a su vez mediante reglas, so pena de caer en un regreso al infinito que imposibilitaría el mismo ejercicio de la facultad. Se trata así de una facultad uno reglada" y que, por tanto, sólo puede caracterizarse como "un talento especial que no puede ser enseñado sino sólo ejercitado; por ello, constituye lo específico del llamado ingenio natural (Mutterwitz) cuya carencia ninguna escuela puede suplir ${ }^{19}$. El Juicio no es objeto de instrucción a la manera del proceder reglado del entendimiento, sino que sólo puede fomentarse mediante un ejercicio que ya siempre presupone su presencia como "don natural» ${ }^{20}$. De ahí la importancia que Kant concede a los ejemplos para el cultivo del Juicio en gene$\mathrm{ral}^{21}$, y a las narraciones biográficas ejemplares para el Juicio moral en especial ${ }^{22}$. Claramente el Juicio kantiano, en tanto que capacidad de interpretar los casos para subusumirlos en conceptos-reglas generales que se ejercita pero no se aprende, ocupa el mismo lugar que la phrónesis-prudentia en la tradición clásica.

Pues bien, en tanto que la buena voluntad es la que se decide por lo universal, resulta que la bondad humana se vertebra esencialmente sobre la capacidad de juzgar que todo hombre posee connaturalmente y ejercita inmediatamente. Nos vemos así remitidos al supuesto del propio análisis transcendental: es en la juzgar".

${ }^{16}$ Siguiendo la costumbre, utilizamos la mayúscula (Juicio) para referirnos a la «facultad de

${ }^{17} \mathrm{KrV} \mathrm{A} 132 / \mathrm{B} 171$.

${ }^{18} \mathrm{KpV}$ (Ak, V, 67).

${ }^{19} \mathrm{KrV}, \mathrm{A} 133 / \mathrm{B} 172$.

${ }^{20}$ Ibíd.

${ }^{21} \mathrm{KrV}, \mathrm{A} 134 / \mathrm{B} 173$.

${ }^{22} \mathrm{KpV}(\mathrm{Ak}, \mathrm{V}, 154)$. 
inmediatez del sano entendimiento humano -en tanto que Juicio-phrónesis o sentido común (gemeinschaftlicher Sinn) ${ }^{23}$ - donde tiene lugar ya siempre la decisión por lo universal y el surgimiento de las reglas morales. Se entiende así que, cuando en el apartado de la Típica del Juicio puro práctico Kant aborda explícitamente el tema de cómo es posible el Juicio práctico, la respuesta no consista más que en explicitar la fórmula que cada hombre está siempre aplicando:

«La regla del Juicio bajo las leyes de la pura razón práctica es esta: pregúntate si la acción que proyectas, si tuviera que ocurrir según una ley de la naturaleza de la que tu mismo fueras parte, podrías ciertamente considerarla posible por tu voluntad. De hecho, según esta regla, cada cual juzga si las acciones son moralmente buenas o malas... Así juzga incluso el entendimiento más común, pues la ley natural se encuentra en la base de todos sus juicios más habituales, incluso los de experiencia" ${ }^{24}$.

Ahora bien, si la buena voluntad remite al Juicio como facultad espontánea y común, ¿no se reduce con ello el "deber ser" de la ley a la facticidad empírica de un enjuiciamiento meramente individual y subjetivo? La respuesta sería afirmativa si hablar de sentido común, entendimiento común o espontaneidad del Juicio significara hacerlo necesariamente de una capacidad que juzga según meros criterios privados e interesados. Pero, tal como el mismo Kant analiza detenidamente en la tercera crítica, lo propio de esta facultad es su constitución intersubjectiva, pues el Juicio exige en su misma operatividad inmediata que cada cual se ponga en el lugar del otro:

«[Las máximas del entendimiento humano común] son las siguientes: (1) pensar por uno mismo; (2) pensar en el lugar de cualquier otro; (3) pensar siempre de acuerdo con uno mismo ${ }^{25}$.

Dada, pues, la estructura intersubjetiva del Juicio, se entiende perfectamente que la buena voluntad enlace con el entendimiento común sin perjuicio de la exigencia de universalidad de la ley moral, sino más bien como su garantía, pues el ejercicio adecuado del Juicio-phrónesis consiste justamente en determinarse desde criterios de universalidad intersubjetiva, esto es, haciendo que la máxima pueda ser pensada como válida para todos ${ }^{26}$.

${ }^{23} \mathrm{KU}, \$ 40(\mathrm{Ak}, \mathrm{V}, 293-296)$.

${ }^{24} \mathrm{KpV}(\mathrm{Ak}, \mathrm{V}, 69-70)$.

${ }^{25} \mathrm{KU}, \$ 40(\mathrm{Ak}, \mathrm{V}, 294)$.

${ }^{26}$ Para esta íntima relación entre la comunicabilidad e intersubjetividad del Juicio y la moralidad, véase la excelente introducción de A. Philonenko a su traducción: Kant, Qu'est-ce que s'orienter dans la pensée, Paris, J. Vrin, 1993. 
Pues bien, justamente porque la bondad surge y se ejerce en la buena voluntad que juzga desde la exigencia común de universalidad intersubjetiva, se entienden dos aspectos que acompañan constantemente y caracterizan la reflexión ética kantiana. Por un lado, (1) que si desconectamos la razón humana de su extralimitación especulativa -i.e. del momento metafísico que históricamente se ha adherido a las escuelas morales-, haya un acuerdo de fondo fundamental en las normas morales básicas que constituyen patrimonio común de la humanidad ${ }^{27}$. Y, por tanto, (2) que la filosofía transcendental en el ámbito moral, al poner justamente entre paréntesis tales aspectos especulativo-teóricos y centrarse en la posición inmediatamente prática de la razón humana en general, no pretenda fundar ninguna nueva moral, sino limitarse a sacar a la luz el principio rector de la moralidad en el lugar que le es propio: la exigencia de intersubjetividad de la ley que determina en su base el ejercio inmediato de la racionalidad (Juicio, entendimiento común).

Este enraizamiento de la moralidad (bondad humana) en la buena voluntad que juzga intersubjetivamente permite subrayar otro aspecto frecuentemente mal interpretado de la reflexión moral kantiana. Es evidente que el momento que da valor moral a la máxima es la posibilidad de ser pensada como válida para todos y, en este sentido - y sólo en este sentido_- el "fundamento» de la moral consiste en la "forma» de la universalidad que debe articular toda máxima. Pero ello no implica que Kant sostenga que la moral (el conjunto de reglas universales) sea "formal» (vacío de contenido): justo al contrario, la moral es siempre "concreta" ${ }^{28}$, i.e. consiste en aquellas máximas sobre determinadas situacions conductuales que pensamos son universalizables ${ }^{29}$ :

"Pues bien, es innegable que todo querer ha de tener también un objeto, i.e. una materia; pero ésta no es por ello el fundamento de determinación ni la condición de la máxima... Por tanto, ciertamente la materia de la máxima puede permanecer, pero no ha de ser la condición de la misma, pues si lo fuera no valdría como ley. Así pues, la mera forma de una ley que limita la materia

${ }^{27}$ De hecho, para Kant, el horizonte moral resultado del proceso de universalización histórico-cultural producido en la convergencia entre helenismo y cristianismo.

${ }^{28}$ Digo "concreta" porque decir "material" podría inducir a un equívoco con el sentido que da Kant al término (KpV; Ak, V, 22): "material" en tanto que sinónimo de egoista implica un Juicio que no atiende al segundo criterio que rige su ejercicio ("pensar en el lugar de cualquier otro").

${ }^{29}$ Esta observación es de todo punto necesaria para una adecuada discusión entre el texto kantiano y las llamadas habitualmente morales materiales (Aristóteles o Scheler). 
ha de ser a la vez un fundamento para añadir esta materia a la voluntad, pero no para presuponerla" ${ }^{30}$.

El cambio de pespectiva que significa pasar de analizar el «fundamento" de la moralidad (ley, razón pura práctica) a ocuparse de la moralidad concreta (sistema de normas, vida moral) es lo que separa la Crítica de la razón práctica de la Metafisica de las costumbres. Por ello, la reconstrucción del modo de vida (éthos) que comporta la bondad humana debemos hacerlo a partir de este último texto.

¿Qué significa en la vida del hombre real conducirse según la buena voluntad, i.e. según las exigencias prácticas intersubjetivas del Juicio? Lo que se opone al principio moral de la universalización de las máximas es el principio del amor propio o egoismo ${ }^{31}$. Pues bien, en la medida que en el hombre real coexiste la voz interior de la ley con los móviles patológicamente afectados, la vida moral sólo puede consistir en someter sus tendencias egoístas a la ley y hacer de tal sometimiento el principio determinante de la acción. De ello se siguen dos consecuencias fundamentales. Por un lado, la conocida diferenciación entre legislación jurídica y mora ${ }^{32}$ : mientras la primera no introduce el deber como motivo determinante de la acción y se limita a exigir un cumplimiento "externo" de la ley con independencia del móvil o intención subjetiva, la segunda implica necesariamente este elemento "interior" pues se trata justamente de que la acción no sea hecha por egoismo. Pero también hay una segunda consecuencia que, aunque no tan subrayada, es de capital importancia para nuestro tema: justamente porque el hombre real (ser racional finito) ha de someter su sensibilidad patológica a la exigencia universal de la ley, él propiamente nunca es autónomo sino que, en todo caso, ha de hacerse autónomo, ha de esforzase constantemente por alcanzar la autonomía. Lo autonomía en sentido absoluto se dice sólo de la "pura razón prácticas ${ }^{33}$ que, como pura idea pensable, suministra un ideal, un télos último a alcanzar: el ideal de santidad ${ }^{34}$. La vida moral real, pues, consistirá en

${ }^{30} \mathrm{KpV}(\mathrm{Ak}, \mathrm{V}, 34)$.

${ }^{31} \mathrm{KpV}$ (Ak, V, 21-22).

${ }^{32}$ Metafisica de las costumbres (Ak, VI, 382).

${ }^{33} \mathrm{KpV}$ (Ak, V, p. 33).

34 «Esta santidad de la voluntad es, empero, una idea práctica que necesariamente ha de servir de modelo, de modo que lo único que corresponde a todos los seres racionales finitos es aproximarse a él en el infinito..." ( $\mathrm{KpV}$; Ak, V, 32). 
la aproximación al ideal de la santidad en tanto que control y coacción del egoismo, con lo cual la bondad humana no es tanto autonomía cuanto «autocracia", dominio sobre uno mismo. Por tanto, el éthos propio del hombre moral sólo puede definirse como la tensión y el esfuerzo continuados en pro de su perfección. Ello es justamente lo que los antiguos entendían por areté-virtus y, en este mismo sentido, también para Kant la vida moral sólo puede entenderse como el ejercicio de la virtud, de manera que una doctrina filosófica de esa vida moral ha de plantearse como una "doctrina de la virtud":

«Para seres finitos santos (que jamás pueden ser tentados a violar el deber) no se da ninguna doctrina de la virtud (Tugendlebre), sino meramente una doctrina de las costumbres (Sittenlehre) que es una autonomía de la razón práctica, mientras que la primera contiene a la vez una autocracia de la razón, es decir, una conciencia -que, aunque no sea percibida directamente, deriva del imperativo categórico moral- de la capacidad de convertirse en señor de las inclinaciones opuestas a la ley, de modo que la moralidad humana en su nivel más elevado no puede ser otra cosa que virtud.... ${ }^{35}$.

En perfecta continuidad, pues, con la tradición clásica, la bondad se realiza como virtud. $Y$ en la media que, como indicábamos antes, la exigencia formal de universalidad ha de aplicarse a la materialidad de situaciones dispares sobre las cuales el Juicio determina las normas a seguir, una doctrina de la virtud deviene necesariamente una doctrina de las virtudes. De aquí la estructura del texto de la Metafisica de las costumbres en su parte moral: sistematización y caracterización de las diversas virtudes y deberes. Y como el criterio de la universalización permite establecer dos grandes objetivos de la conducta humana, la perfección propia y la felicidad ajena ${ }^{36}$, la lista tradicional de las virtudes puede sistematizarse con arreglo a estos dos fines últimos.

De este modo, Kant puede integrar en su filosofía moral la temática de officiis y de beneficiis en el sentido más clásico. Por un lado tenemos los "deberes para consigo mismo ${ }^{37}$ o virtudes tendendes a la propia perfección: la conservación de la propia vida; la moderación en el comer, beber, sexualidad; evitar los vicios de la mentira, la avaricia, la bajeza o falsa humildad; fortalecimiento de la recta conciencia frente a la presunción y escrupulosidad; culti-

\footnotetext{
${ }^{35}$ Metafisica de las cotumbres (Ak, VI, 383).

${ }^{36}$ Ibíd. (Ak, VI, 385).

${ }^{37}$ Ibid. (Ak, VI, 417ss.).
} 
vo de las propias fuerzas tanto corporales (gimnasia) como espirituales (educación y formación). Y por otro, los "deberes de virtud para con los otros" ${ }^{38}$ o tendentes a la felicidad ajena: el amor en tanto que bondad y compasión; el respeto a los otros evitando vicios como el orgullo, la maledicencia, la mofa; la sociabilidad; la amistad humana en general y la amistad moral en particular.

¿Cuál es el saber propio del hombre que, según los dictámenes de la buena voluntad y el Juicio, se esfuerza por realizar la virtud? Si por "saber" entendemos «saber de la naturaleza», es claro que la moralidad no aporta nada que pueda modificar ni incrementar el conocimiento del mundo natural en tanto que realidad fenoménica. En este sentido, una de las consecuencias centrales de la primera crítica -en modo alguno alterada por los textos kantianos posteriores- es la plena autonomización del conocimiento científico-natural, tanto respecto de las tutelas metafísicas como de cualquier otra índole: en su uso teórico el canon de la razón pura no es otro que la analítica del entendimiento como marco de toda experiencia posible ${ }^{39}$; no hay más certeza ni saber "objetivo" que el suministrado por la síntesis categorial de la experiencia espacio-temporal en tanto que ámbito de aparición de la cosa para nosotros ${ }^{40}$; una "doctrina de la ciencia" (Wissenschaftslehre) no puede consistir más que en establecer los principios transcendentales del fenómeno en tanto que verdadera "gramática" de la experiencia ${ }^{41}$.

Ahora bien, si por saber entendemos "saber del mundo" (Weltweisheit), la cuestión es muy distinta, pues el "mundo" es bastante más que la experiencia objetiva. Y ello no sólo porque el conocimiento fenoménico, por ser precisamente sintético, nunca alcanza el todo de la misma naturaleza, sino por otra razón más importante aún: el mundo también es el lugar donde hay que construir las exigencias de la libertad y, por tanto, en tanto que "mundo moral" no sólo con-

${ }^{38}$ Ibid. (Ak, VI, 448ss.).

${ }^{39} \mathrm{KrV}, \mathrm{A} 796 / \mathrm{B} 824$.

${ }^{40} \mathrm{KrV}$ A 822/B 850.

${ }^{41}$ Progresos de la Metafisica (Ak, XX, 260). 
siste en lo que es, sino mucho más esencialmente en lo que ha $\mathrm{de} \operatorname{ser}^{42}$. En este sentido, un saber del mundo significa un saber sobre la incardinación de la libertad en la naturaleza, sobre la compatibilidad entre la realidad natural y la realizabilidad de las metas morales, sobre "qué me está permitido esperar si actúo tal como debo" "43. Y claramente, un saber de estas características no es nunca natural ni fenoménico, sino que, en todo caso, "transita» entre naturaleza y libertad ${ }^{44} y$, moviéndose entre ambas esfera, se eleva a la idea total de mundo que el conocimiento objetivo nunca puede alcanzar, mereciendo así el nombre de «sabiduría».

Pues bien, es evidente que un saber en este segundo sentido no sólo tiene que ver con el hombre moral, sino que su misma condición de posibilidad depende de la moralidad. Denunciada y arruinada la falacia naturalista por Hume, es claro que ya no hay posibilidad de argumentar sobre del «deber ser» a partir del "orden natural" como de un modo u otro se hacía en la filosofía moral y el iusnaturalismo de corte aristotélico. Es decir, cuál deba ser el mundo a construir y en qué medida la realidad fenoménica sea un instrumento apropiado al efecto, sólo puede determinarse desde las metas fijadas por la razón práctica en tanto que ejercicio intersubjetivo del Juicio. Por tanto, una «doctrina de la sabiduría" (Weisheitslehre) contendrá todos aquellos enunciados sobre el mundo que tienen un fundamento moral ${ }^{45}$, y en ella se transitará de la naturaleza a la libertad:

«Así pues, lo que es imposible en una consideración teórica (esto es, el progreso de la razón a lo suprasensible del mundo), allí (mundus noumenon) vivimos (esto es, en el máximo bien derivado); aquello es, pues, efectivo en una consideración práctica, a fin de colocar el curso de la vida del hombre aquí en la tierra en igualdad con el curso en el cielo. Se puede y se debe suponer el mundo, según analogía con la teleología física que nos permite percibir la naturaleza, como determinado $a$ priori (incluso independientemente de aquella percepción) para coincidir con el objeto de la teleología moral (esto es, con el fin final de toda cosa según las leyes de

42 "Denomino al mundo, en tanto que fuera adecuado a todas las leyes morales (tal como puede serlo según la libertad de los seres racionales y como debería serlo según las leyes necesarias de la moralidad, un mundo moral... En tal medida es, pues, una mera idea, pero una idea práctica que puede $y$ ha de tener efectivamente su influencia en el mundo sensible para hacerlo lo más adecuado posible a esa idea" (KrV A 808/B836).

${ }^{43} \mathrm{KrV}, \mathrm{A} 805 / \mathrm{B} 833$.

${ }^{44} \mathrm{KU}(\mathrm{Ak}, \mathrm{V}, 175-176,178-179)$.

${ }^{45}$ Progresos de la Metafisica (Ak, XX, 294). 
la libertad). Y ello a fin de perseguir la idea del máximo bien que, como producto moral, exige al mismo hombre (en tanto que está en su poder) como creadorn ${ }^{46}$.

Sin pretender aquí agotar las extensas y complejas implicaciones de esta temática ${ }^{47}$, es necesario ofrecer al menos un inventario de la cuestión tal como Kant la desarrolla entre la Dialéctica de la KpV, la Doctrina del Método de la KU, los Progresos de la Metafisica de 1791 y los opúsculos de filosofia de política y de la historia.

De cuanto llevamos dicho se desprende, en primer lugar, que las metas determinantes de lo que deba ser el mundo a construir vendrán dadas por aquella exigencia de universalidad intersubjetiva que debe conformar el contenido de nuestras máximas. En tal sentido, la moralidad genera para Kant un auténtico «sistema de fines " ${ }^{48}$ : por el uso interno de la libertad respecto a la intención de la acción surgen los fines de la virtud ya comentados anteriormente (perfección propia, felicidad ajena); por el uso externo de la libertad en el ámbito coactivo de la ley pública surgen los fines del derecho y, especialmente, los del derecho político y de gentes (constitución republicana, federación de estados, paz perpetua).

Si los fines del derecho han de ser realizables, ello presupone que el orden natural en que se mueve nuestra existencia física pueda ser pensado como adecuado y compatible con tales metas, es decir, que la causalidad fenoménica pueda ser entendida como dispuesta en función de los fines de la razón práctica: se supone, en suma, la posibilidad de una consideración teleológica de la naturaleza. Justamente uno de los temas centrales de la tercera crítica es elaborar tal concepción y fijar sus límites en tanto que "modo de reflexión» diferenciado del conocimiento científico. Pues bien, la idea de una "técnica de la naturaleza” permite unificar el principio del mecanicismo natural con la teleología ${ }^{49}$, de modo que la noción de finalidad es un "principio subjetivo de la razón para nuestro Juicio que, como regulativo (no constitutivo), vale para nuestro Juicio humano tan necesariamente como si fuera un principio objetivo" ${ }^{50}$. Esta consi-

46 Ibíd. (Ak, XX, 307-308).

${ }^{47}$ Me he ocupado ampliamente de ello en: Tránsito de la naturaleza a la historia en la filosofia de Kant, Barcelona, Anthropos, 1996.

48 Véase en este sentido la lectura teleológico-objetiva de la ética kantiana formulada por $\mathrm{R}$. Langthaler en Kants Ethik als "System der Zwecken, Berlin, De Gruyter, 1991.

${ }^{49} \mathrm{KU}, \$ 78$ (Ak, V, 410).

${ }^{50} \mathrm{KU}, \S 76(\mathrm{Ak}, \mathrm{V}, 404)$. 
deración teleológica permite interpretar las disposiciones naturales (en nosotros y fuera de nosotros) como orientadas al desarrollo de la cultura de las habilidades y de la disciplina cuyo último nivel es justamente el establecimiento de un orden jurídico cosmopolita ${ }^{51}$ : se abre así la posibilidad discursiva de leer el orden natural como dinamismo dispuesto para la realización de los fines del derecho en tanto que esquema rector de la filosofía de la historia ${ }^{52}$.

A su vez, si el fin de la virtud en lo que respecta a la perfección propia ha de ser realizable, dado que tal fin implica la eliminación completa de los elementos egoístas opuestos a la moralidad, mientras que nuestra finitud comporta siempre una propensión al egoísmo, su efectuación sólo es pensable mediante el esquema temporal de un progreso infinito: «este progreso infinito, empero, sólo es posible bajo la presuposición de una existencia y personalidad del mismo ser finito que perdura al infinito (lo cual se denomina inmortalidad del alma) ${ }^{53}$.

La comprensión de la naturaleza y la historia como orientadas teleológicamente a la consecución del derecho y la idea de una serie temporal indefinida para la realización de la virtud comportan pensar la totalidad del mundo (sensible y suprasensible) como dipuesto para la efecutación del bien supremo moral. Ahora bien, que la existencia del mundo tenga un sentido moral sólo es pensable bajo un último supuesto, a saber: que el origen del mundo remita, no sólo a una causa primera (incluso inteligente), sino a un ser absolutamente moral, Dios: «consecuentemente debemos aceptar una causa moral del mundo (un creador del mundo) para suponer un final final adecuado a la ley moral; y, en la medida que esta última es necesaria, es igualmente necesario (en el mismo grado y a partir del mismo fundamento) aceptar la primera, a saber, que hay un Dios ${ }^{54}$

La filosofía de la historia y los postulados de la inmortalidad del alma y la existencia de Dios constituyen, pues, la sabiduría del hombre moral. Si contrastamos esta sabiduría con la del simple conocimiento teórico de la naturaleza, la diferencia resulta evidente: allí donde la ciencia se limita a darnos regula-

${ }^{51} \mathrm{KU}, \$ 83$ (Ak, V, 429-434).

52 Para una ampliación de esta temática véase mi estudio Lliçons sobre historia i dret a Kant, Barcelona, Edicions UB, 1997.

${ }^{53} \mathrm{KpV}$ (Ak, V, 122).

${ }^{54} \mathrm{KU}, \$ 87$ (Ak, V, 450). 
ridades fenoménicas sin tan siquiera alcanzar su unidad física total, la sabiduría nos sitúa delante de una totalidad provista, además, de sentido moral. Mientras que el conocimiento científico se limita a moverse en una naturalezamáquina sin finalidad ni sentido —si queremos, los restos materiales del derrumbamiento del universo aristotélico-cristiano-, sólo la sabiduría afirma propiamente que hay mundus: frente a la «inmundicia» aterradora de los agregados de materia moviéndose en el espacio infinito ${ }^{55}$, el hombre moral sostiene que hay orden porque hay realización del bien y, por tanto, con cierta semejanza a la sabiduría de los antiguos, se puede volver a hablar de kósmos kalós kai agathós (según se contemple desde Juicio estético o el teleológico). Y, porque el hombe moral supone que hay mundo, en lugar de caer en la desesperación escéptica ante los absurdos de la naturaleza y de la historia (Voltaire), o refugiarse en la contemplación more aeternitate de las cosas (Spinoza), o huir del mundo por el salto moral de la fe (Jacobi), puede confiar en la providencia y perseverar en su acción moral:

«Es, pues, de la máxima importancia estar satisfecho con la providencia (aunque nos haya proyectado un camino de tanto esfuerzo sobre la tierra): en parte para mantener siempre el valor en medio de tantas penalidades, en parte para no culpar al destino y tener siempre presente nuestra culpa, que quizá es la única causa de todos aquellos males, y de este modo no desentendernos de nuestro perfeccionamiento como remedio contra todo ello... Y este es el fruto de la historia de la humanidad primitiva esbozada por la filosofía: satisfacción con la providencia y con el curso de las cosas humanas en su conjunto, que no avanzan del bien al mal, sino que se desarrollan lentamente de peor a mejor; progreso al que cada cual está llamado a colaborar por la misma naturaleza en la medida que corresponda a sus fuerzas ${ }^{56}$.

Es claro, pues, el paralelismo entre la temática kantiana de la filosofia de la historia y de los postulados prácticos con la sabiduría de las escuelas helenísticas y el humanismo antiguo en general ${ }^{57}$. Juicio, prudencia, virtud, bien supremo, sistema de fines, finalidad moral del mundo, confianza en la providencia, sabiduría moral, etc., ¿̇no nos retrotraen al núcleo mismo del modelo cosmológico timeico — unidad físico-ética del mundo supralunar reflejada en la vida buena

55 "El silencio eterno de estos espacios infinitos me aterra" (Pascal, Pensamientos, 91).

${ }^{56}$ Presumible inicio de la historia humana (Ak, VIII, 121, 123).

${ }^{57}$ Véase al respecto: JM. MUGLIONI, La philosophie de l'histoire de Kant, París, PUF, 1993. 
del sabio en el mundo sublunar ${ }^{58}$ - que, incorporándose al cristianismo, determinó la sabiduría del mundo imperante hasta la modernidad galileano-cartesiana? ¿Será así el último resultado de la crítica transcendental, por lo que se refiere a la sabiduría inherente a la bondad humana, una "restauración" del modelo timeico y, por tanto, vollens nollens una recaída del kantismo en el dogmatismo ingenuo de la metafísica cosmológico-moral antigua y medieval?

Para responder este interrogante es conveniente recordar una de las observaciones iniciales: el entendimiento humano común (sentido común, razón general, Juicio) tiene su esfera exclusiva de competencia —es canónico- en el ámbito de la decisión práctica en tanto que su estructura constitutiva viene dada por la exigencia de universalidad intersubjetiva, mientras que en el ámbito especulativo-teórico tiene la tendencia natural a extraviarse cuando sobrepasa los límites de la experiencia (apariencia transcendental), debiendo ser disciplinado por la crítica filosófica. Apliquémoslo a nuestro tema: ciertamente el entendimiento común - impulsado por su constitución moral - tiende de suyo a considerar que el mundo es un dinamismo teleológico encaminado al bien supremo (jurídico y moral), pero tal tesis no se sustenta en la manifestación de la cosa misma (la totalidad de la naturaleza o de la historia, los planes de la providencia, etc.), pues tales entidades no son ni pueden ser nunca "objetos" de experiencia, y, por tanto, no se trata de una afirmación con validez "objetiva" sino de una exigencia (subjetivo-necesaria, ciertamente) de nuestra constitución moral. $\mathrm{Y}$ a una tesis que no tiene fundamento objetivo sino subjetivo corresponde un estatuto de certeza de "creencia racional $"$ "

Por tanto, la sabiduría timeica de los antiguos sería el ejemplo paradigmático del exceso metafísico espontáneo del entendiento común: el hombre bueno hipostasia ingenuamente sus exigencias morales (razonables ciertamente) en un pretendido conocimiento objetivo del mundo y así convierte lo que es una consideración subjetiva - sólo podemos pensar el mundo como marco de nuestra acción moral si lo suponemos estructurado en función del bien supremo- en una afirmación teórico-apodíctica - el mundo está estructurado en función del bien supremo- En cambio, el hombre moral que ha pasado por la crítica filosófica y no olvidemos que en su dimensión teorética "la ciencia (críticamente buscada y

${ }^{58}$ R. BRAGUE, op. cit., p. 41 ss.

${ }^{59} \mathrm{KrV}$, A 822/B 850.

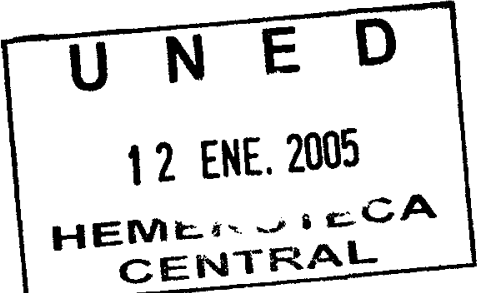


metódicamente dirigida) es la puerta estrecha que conducte a la doctrina de la sabiduría ${ }^{60}$ - ha de aceptar lúcidamente que su sabiduría del mundo es sólo la humanamente posible, es decir, aquella que viene exigida por su constitución moral y cuya razonabilidad no puede ser confundida con la objetividad científica:

«Este argumento moral no puede ofrecer ninguna prueba objetivamente válida de la existencia de Dios, no puede probar a quien duda que Dios existe. No obstante, prueba que, si éste quiere pensar de forma moralmente consecuente, ha de suponer aquel principio entre las máximas de su razón práctica» ${ }^{61}$.

En consecuencia, la sabiduría del mundo del hombre moral que ha incorporado la crítica a su saber consiste en reducir el componente dogmático-especulativo de la sabiduría antigua a su dimensión legítima. Ni la armonia celeste ni la distribución matemática de la materia ni el orden cosmológico en general son pruebas objetivas de la bondad de un mundo cuyo reflejo en el microcosmos sería el equilibro anímico del sabio. Justo al revés: la bondad es atributo exclusivo del hombre, y como los fines morales exigen su realización en el mundo, se puede suponer lícitamente que el mundo se adecua a ellos. En perfecta coherencia con el proceder transcendental se da también aquí un giro copernicano: la bondad no es ningún predicado objetivo del mundo ni de las cosas, sino una cualidad del sujeto que le permite mirar el mundo de un cierto modo si quiere mantener la coherencia consigo mismo.

Si hay un lugar donde la coincidencia/diferencia entre la sabiduría kantiana y la sabiduría de los antiguos se muestra en toda su sutileza, es en el conocido pasaje sobre el cielo estrellado sobre mí y la ley moral en mi que cierra la segunda crítica ${ }^{62}$. En una primera lectura, el texto aparenta moverse en perfecta continuidad con el modelo timeico: a la infinitud exterior de los mundos, sistemas y movimientos estelares corresponde la infinitud interior de las tareas morales a

${ }^{60} \mathrm{KpV}(\mathrm{Ak}, \mathrm{V}, 163)$.

${ }^{61} \mathrm{KU}, \$ 87$ (Ak, V, 450-451). Obsérvese cómo aquí Kant ofrece, incluso en la forma expresiva, una reconstruccion en clave moral del argumento anselmiano: no es la razón teórica quien entra en contradicción consigo misma si niega Dios, sino la razón práctica. Diríamos en términos actuales: la negación de Dios comporta una contradicción perfomativa con la vida del hombre moral. Dicho sea de paso, con esta reelaboración práctica del argumento ontológico, Kant se muestra mejor lector del texto bíblico que el obispo de Caterbury, pues el salmista no situa la negación de Dios en un contexto especulativo-teórico sino en uno estrictamente motal: «Dice en su corazón el insensato: No hay Dios. Corrompidos están, de conducta abominable, no hay quien haga el bien" (Salmo 13, 1).

${ }^{62} \mathrm{KpV}(\mathrm{Ak}, \mathrm{V}, 161-162)$. 
realizar, de modo que la correspondencia entre ambos infinitos parece indicar una disposición armónica, ajustada y buena de todo lo existente, reafirmándose así el principio determinante de la cosmología moral antigua.

Ahora bien, una lectura más atenta del pasaje muestra lo erróneo de la aparente correspondencia: la infinitud exterior es la de la simple materia en movimiento (naturaleza, fenómeno) que «aniquila mi importancia como criatura animal que ha de devolver al planeta (un mero punto en el universo) la materia de que está hecha", mientras que la infinitud interior «eleva mi valor como inteligencia infinitamente por mi personalidad, en la cual la ley moral me manifiesta una vida independiente de la animalidad e incluso de todo el mundo sensiblem. Se trata, pues, de dos infinitudes completamente heterogéneas: si la primera es la de la naturaleza en su sucesión espacio-temporal indefinida, la segunda, en tanto que pone un valor absoluto en uno de los elementos materiales (el sujeto moral), rompe con aquélla e instaura una tarea infinita completamente antinatural, la de realizar el mundo moral. No obstante, y a pesar de su heterogeneidad, también es cierto que de algún modo Kant refiere una a la otra. ¿En qué consiste, adecuadamente entendida, la correspondencia de tal heterogeneidad?

Claramente, la infinitud exterior que me aniquila no puede en absoluto disminuir la percepción de mi valor y dignidad morales por encima de aquella naturaleza. Pues bien, según la analítica de Juicio estético, tal es justamente la estructura definitoria de lo sublime: decimos de un fenómeno desproporcionado de la naturaleza que es sublime cuando, aún pareciendo infinitamente pequeños a su lado, reconocemos nuestra superioridad moral respecto a él. En el juicio de lo sublime natural se produce, pues, una subrepción ${ }^{63}$ : la inmensidad exterior no admira por ella misma, sino porque nos descubre nuestra interioridad moral infinitamente más valiosa, convirtiénose entonces la infinitud exterior en símbolo o analogía de la moralidad. Tal es precisamente el papel del cielo estrellado en el texto que comentamos: no se trata de un juicio objetivo sobre la naturaleza, sino de una valoración estética. Si conceptualizamos el cielo estrellado como sublime no es porque tenga bondad en sí mismo, sino porque nos permite reconocer nuestra propia infinitud moral. La naturaleza, objetivamente, no es ya kalós kai agathós, su belleza-orden-sublimidad es una simple proyección externa del único foco que propiamente irradia orden, el sujeto en su tarea por construir un mundo que sea auténticamente moral.

${ }^{63} \mathrm{KU}, \$ 27(\mathrm{Ak}, \mathrm{V}, 257)$. 
¿Qué significado último tiene, pues, la sabiduría kantiana del hombre moral en tanto que afirmación razonable pero subjetiva del orden del mundo? ¿Habremos de concluir, siguiendo la interpretación ya clásica de Vaihinger ${ }^{64}$, que Kant remite en última instancia a un "como si" cuya finalidad, en clara anticipación a Nietzsche, es pura voluntad constructora de mundo? ¿ $\mathrm{O}$, en una línea más atenuada, habremos de reconocer con Lyotard ${ }^{65}$ que se trata de un típico meta-relato justificativo de la modernidad para instaurar su concepción de la racionalidad y la verdad? ¿ $\mathrm{O}$, quizá, en las antípodas de ambas lecturas, deberemos denunciar con Kojève ${ }^{66}$ que, frente a Hegel, «Kant mismo no pudo o no quiso elevarse a la Sabiduría, puesto que por motivos religiosos no quiso admitir la eficacia de la actividad libre o consciente del hombre en el mundo $y$, por consiguiente, rechazó identificar la Verdad (discursiva) con la Historian? A mi parecer ni lo uno ni lo otro. Frente al primer tipo de lectura, conviene subrayar la función terapéutica que cumple la sabiduría del mundo en continuidad con la consolatio philosophiae de los antiguos - fortalece el carácter y nos hace perseverar en el ejercicio de la virtud frente a las adversidades del destino-, sólo que ahora - por su inserción en el proyecto crítico-ilustrado- tal sabiduría alcanza la suficiente madurez como para desvelarnos su fundamento moral y no teóricoobjetivo. Frente al segundo, basta con recordar las mismas palabras de Kant: «yo, pobre hijo de la tierra, no estoy en absoluto organizado para el lenguage de Dios de la razón intuitiva” ${ }^{67}$.

${ }^{64} \mathrm{H}$. Vaihinger, Die Philosophie des Als-ob, Berlín, Reuther \& Reichard, 1911.

${ }^{65}$ F. Lyotard, L'enthousiasme. La critique kantienne de l'histoire, Paris, Galilée, 1986.

${ }^{66}$ A. Kojève, Kant, París, Gallimard, 1973, p. 218.

${ }^{67}$ A Hamann, 6.4.1774. 